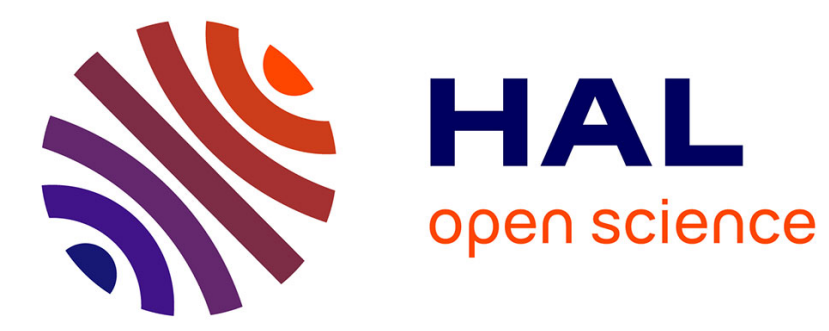

\title{
Spin-Exchange optical pumping in a van
}

Christian Chauvin, Louis Liagre, Céline Boutin, Emilie Mari, Estelle Léonce, G. Carret, Bruno Coltrinari, Patrick Berthault

\section{To cite this version:}

Christian Chauvin, Louis Liagre, Céline Boutin, Emilie Mari, Estelle Léonce, et al.. Spin-Exchange optical pumping in a van. Review of Scientific Instruments, 2016, 87, pp.016105. 10.1063/1.4940928 . cea-01264746

\section{HAL Id: cea-01264746 https://hal-cea.archives-ouvertes.fr/cea-01264746}

Submitted on 29 Jan 2016

HAL is a multi-disciplinary open access archive for the deposit and dissemination of scientific research documents, whether they are published or not. The documents may come from teaching and research institutions in France or abroad, or from public or private research centers.
L'archive ouverte pluridisciplinaire HAL, est destinée au dépôt et à la diffusion de documents scientifiques de niveau recherche, publiés ou non, émanant des établissements d'enseignement et de recherche français ou étrangers, des laboratoires publics ou privés. 


\section{AIP $\mid \begin{aligned} & \text { Review of } \\ & \text { Scientific Instruments }\end{aligned}$}

\section{Note: Spin-exchange optical pumping in a van}

C. Chauvin, L. Liagre, C. Boutin, E. Mari, E. Léonce, G. Carret, B. Coltrinari, and P. Berthault

Citation: Review of Scientific Instruments 87, 016105 (2016); doi: 10.1063/1.4940928

View online: http://dx.doi.org/10.1063/1.4940928

View Table of Contents: http://scitation.aip.org/content/aip/journal/rsi/87/1?ver=pdfcov

Published by the AIP Publishing

\section{Articles you may be interested in}

On the limits of spin-exchange optical pumping of $3 \mathrm{He}$

J. Appl. Phys. 116, 014903 (2014); 10.1063/1.4886583

An all-optical scalar and vector spin-exchange relaxation-free magnetometer employing on-off pump modulation

J. Appl. Phys. 109, 07 E507 (2011); 10.1063/1.3536673

Spin-exchange optical pumping of high-density xenon-129

J. Chem. Phys. 118, 1581 (2003); 10.1063/1.1539042

Spin exchange optical pumping at pressures near 1 bar for neutron spin filters

Appl. Phys. Lett. 80, 2210 (2002); 10.1063/1.1461424

Spin-exchange optical pumping using a frequency-narrowed high power diode laser

Appl. Phys. Lett. 76, 1356 (2000); 10.1063/1.126030

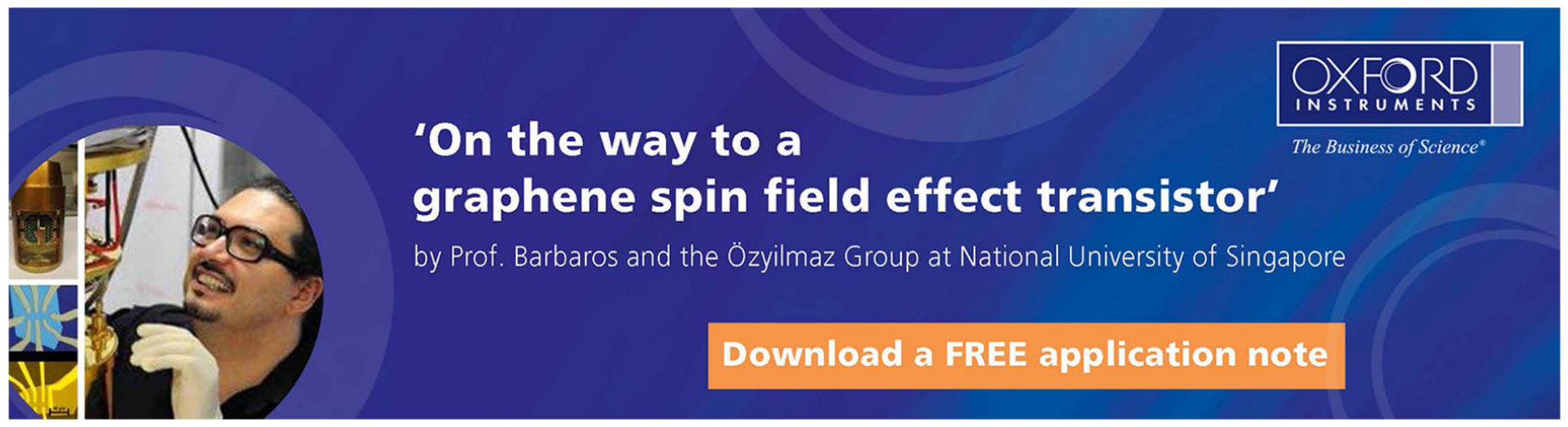




\title{
Note: Spin-exchange optical pumping in a van
}

\author{
C. Chauvin, ${ }^{1}$ L. Liagre,${ }^{1}$ C. Boutin, ${ }^{2}$ E. Mari, ${ }^{2}$ E. Léonce,${ }^{2}$ G. Carret,${ }^{2}$ \\ B. Coltrinari, ${ }^{2}$ and P. Berthault ${ }^{2, a)}$ \\ ${ }^{1}$ SB2SM, CEA, CNRS, Université Paris-Saclay, CEA Saclay, 91191 Gif sur Yvette, France \\ ${ }^{2}$ NIMBE, CEA, CNRS, Université Paris-Saclay, CEA Saclay, 91191 Gif-sur-Yvette, France
}

(Received 9 November 2015; accepted 14 January 2016; published online 28 January 2016)

\begin{abstract}
The advent of spin-hyperpolarization techniques designed to overcome the sensitivity issue of nuclear magnetic resonance owing to polarization transfer from more ordered systems has recently raised great enthusiasm. However, the out-of-equilibrium character of the polarization requires a close proximity between the area of production and the site of use. We present here a mobile spin-exchange optical pumping setup that enables production of laser-polarized noble gases in a standalone mode, in close proximity to hospitals or research laboratories. Only compressed air and mains power need to be supplied by the host laboratory. (C) 2016 AIP Publishing LLC. [http://dx.doi.org/10.1063/1.4940928]
\end{abstract}

The spin-exchange optical pumping (SEOP) technique is based on the transfer of angular momentum from photons to electron spins of an alkali metal (fast process) followed by a polarization transfer from these electron spins to the nuclear spins of a noble gas (slow process). Several reviews explaining the theory and describing theoretical details can be found in the literature. ${ }^{1}$ Whereas in its principle, the SEOP method seems to require only a photon source at the good wavelength (the $\mathrm{D}_{1}$ transition of an alkali metal), a magnetic field collinear to the photon beam, and a cell containing the noble gas and the alkali metal, many more details make that the resulting nuclear polarization can vary by a large factor (from 0.01 to 0.7 ). In the lab, we produce laser-polarized ${ }^{129} \mathrm{Xe}$ (as well as ${ }^{3} \mathrm{He}$ and ${ }^{83} \mathrm{Kr}$ ) for several years via SEOP working in batch mode and use it on the NMR spectrometers of the laboratory. We have decided to extend our application domain and the possibilities for collaborations, and, instead of transporting the frozen hyperpolarized noble gas in a special container, to perform optical pumping directly on site. Indeed on site production is sometimes required, for instance, for hyperpolarized ${ }^{83} \mathrm{Kr}$ where the transport of frozen noble gas is not an option. ${ }^{2}$

Therefore, our device has been conceived in two parts, the coils being separated from the rest of the setup (pumping cell, optics, gas distribution system, pump, power supply, etc.). With this principle, at the difference of the other transportable polarizers proposed in the literature, ${ }^{3-5}$ it becomes possible by keeping only the latter part to use the fringe field of a horizontal MRI magnet to perform in the same place SEOP and imaging.

When hyperpolarized xenon has to be produced in standalone mode (without external magnetic field provided), the part containing the coils must be used (in red in Fig. 1). An ensemble of four coils with diameter of $620 \mathrm{~mm}$ for the two central ones and of $440 \mathrm{~mm}$ for the two outer ones creates a unidirectional magnetic field of $100 \mathrm{G}$ when supplied with

\footnotetext{
a) Author to whom correspondence should be addressed. Electronic mail: patrick.berthault@cea.fr
}

a DC current of 8 A (Electric supply, Delta Electronika), with a field homogeneity better than $10^{-4}$ in a volume of $120 \mathrm{~cm}^{3}$. This large volume renders the operations with the SEOP cell more comfortable, lets open many possibilities dealing with its size and shape, and facilitates the on-flow experiments. An aluminum frame supports these coils. Four foldaway wheels have been added in order to easily move it. At the rear extremity of the frame (Fig. 1, left), a large plastic beaker that slides along a vertical rod enables collection of hyperpolarized noble gas in a removable receptacle.

The second part of the device is contained on a chariot, also in aluminum (in blue on Fig. 1). It contains the laser diodes (1), the electric supply for the coils (2), the heating system (3), the pumping group (4), the plate containing the gas reservoirs and the tubing (5), the polarizer (6), and the SEOP cell (7). The latter is placed on a plateau, which is retractable, thanks to a system of rails and wheels placed under it. While in the transport mode it is in retracted position, it is extended to reach the center of the coils during operation. When the wheels of the device containing the coils are folded away, vertically the two parts fit perfectly together through the sliding plateau and the SEOP cell comes at the exact center of the coils.

The light source consists in a fibered laser diode (Coherent Duo FAP, $2 \times 30 \mathrm{~W}$ maximal power (1)) entering in a circular polarizing unit (Coherent) (6) after having crossed a homogenizer in which the bundle consisting of two $800 \mu \mathrm{m}$ diameter solid-core fibers is transformed into a unique randomly polarized beam with Gaussian shape. The circular polarizing unit essentially consists in a polarization beamsplitter cube, a mirror, and two adjustable quarterwave plates. Photons with one polarization cross the cube and then a quarterwave plate, while photons with the other polarization are reflected by the face of the cube, then by a mirror and cross the other quarterwave plate. The large uniform collimated beams converge at the SEOP cell front face situated $130 \mathrm{~cm}$ away from the polarizer. Behind the cell, a LM100-HTD powermeter connected to a FieldMaster-GS display unit (Coherent) measures the light intensity that has not been absorbed by the alkali vapors. The SEOP cell is in Pyrex. Its shape is inspired by our previous setup, ${ }^{6}$ i.e., heating is 


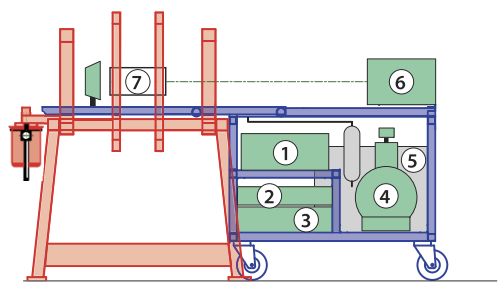

Side view

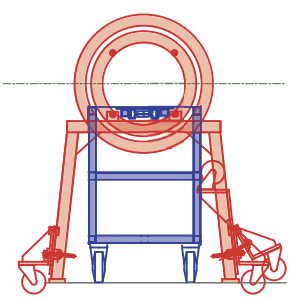

Front view
FIG. 1. Drawing of the SEOP setup, side and front views. For explanation of the indicated numbers, see the main text.

performed by a flow of hot air in a double envelope. The temperature of the air is regulated via a Eurotherm B-VT 2000 unit. In the cell however the input of the gases is different from the exit not only for the heating gas (outer compartment) but also for the inner compartment. The front face of the SEOP cell is a borosilicate glass disk treated to be transparent at $795 \mathrm{~nm}$ (Fichou), corresponding to the $\mathrm{D}_{1}$ line of rubidium. This disk is fixed onto the rest of the cell, thanks to Teflon rings.

Before the SEOP cell is installed on the plateau, some grains of metallic rubidium are introduced into it in a glove box under argon. Then, it is connected to the tubing: upstream to Swagelok plastic tubes, downstream to a glass coil placed just at its output. This glass coil is intended to be thermalized at $-98^{\circ} \mathrm{C}$ by a methanol-nitrogen cooling bath in order to trap potential rubidium traces during the transfer of the gas mixture to the storage reservoir. Afterwards, the SEOP cell is filled with xenon, nitrogen, and helium, sequentially, or from a $1.8 \mathrm{~L}$ bottle containing the mixture already prepared (opposite face of the plate). Typical values for the pressures inside the SEOP cell are 0.1 bars xenon, completed with nitrogen to reach 0.4 bars and then with helium to reach 3.5 bars at room temperature.

The aluminum plate, displayed in Fig. 2, contains several valves and reservoirs. For the arrival of helium (a) from the bottle, a quarter-turn ball valve is sufficient (this gas is used at a super-atmospheric pressure), while for nitrogen (b) and for xenon, quarter-turn ball valves are completed by precision valves (e). Between the quarter-turn valves and the precision valves, the gases cross Sertronics filters (Air Liquide) in order to be purified from $\mathrm{O}_{2}$ or $\mathrm{H}_{2} \mathrm{O}$ traces (opposite side of the plate). Two reservoirs contain natural abundance and $83 \%$ ${ }^{129}$ Xe-enriched xenon (c), while a third one having an output pipe different from the inlet pipe serves to separate xenon from other gases by condensation (d).

A dry scroll vacuum pump (model SH110 from Agilent) enables to reach a primary vacuum in all the gas tubes and serves to separate xenon from helium and nitrogen after optical pumping. When necessary, it can be completed by a turbo-pumping group (model VLP70 from Varian). Pressure is measured in different points of the device through diaphragm gauges (Varian CDG-500) and vacuum gauge controllers (Varian AGC100-DV100). In such a SEOP setup, the limiting factor for producing quickly hyperpolarized xenon is the time required to heat the cell. In order to save time, a derivation system using a hose continuously heated at $70{ }^{\circ} \mathrm{C}$ (Kenovel) has been installed on the heating circuit. It is connected each time a new SEOP experiment starts and disconnected before

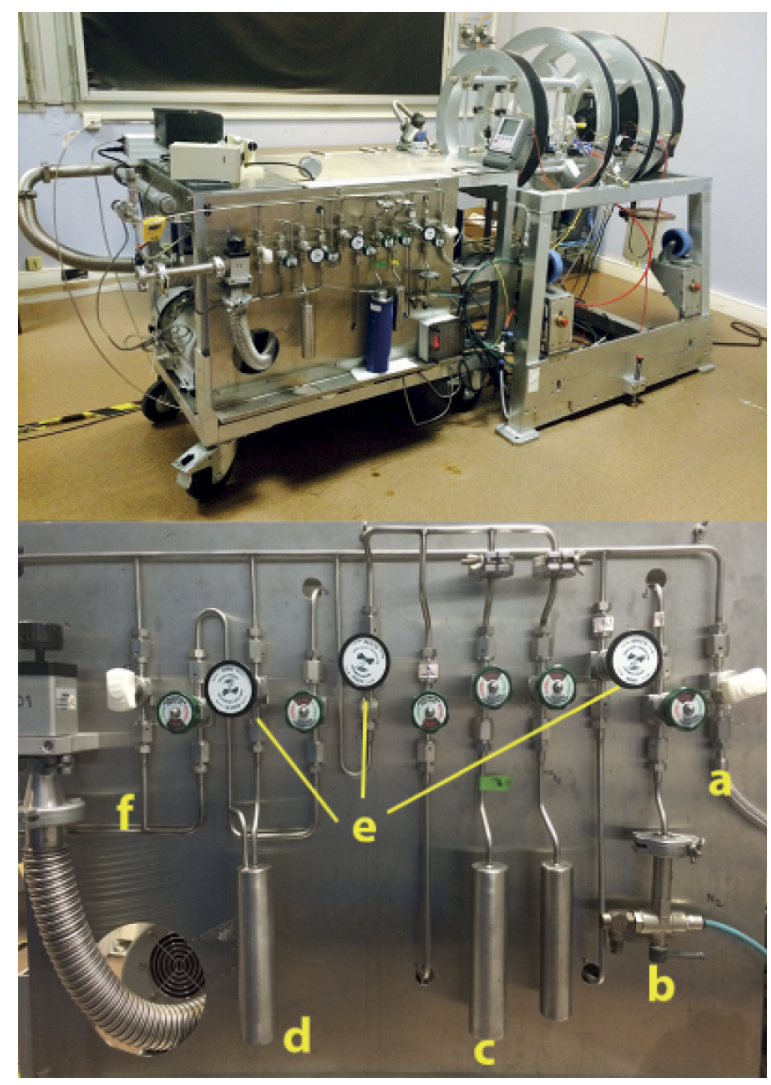

FIG. 2. On-board SEOP System. Bottom: zoom on the aluminum plate for gas storage and distribution.

polarized xenon is collected. The complete SEOP experiment can then be achieved in less than $5 \mathrm{~min}$.

Thanks to the wheels both parts of the device can be easily transported to the interior of a van equipped with a power liftgate. A plywood sheet placed on the van floor enables exact positioning of the aluminum frame legs (after retraction of the wheels). When placed in the van, a minimal distance of $60 \mathrm{~cm}$ between the device and the walls all around the device enables safe operation. In addition to the SEOP setup, during operation, the van compartment contains two chariots. One of these chariots supports the nitrogen and helium gas bottles (20 1-bottles of $\mathrm{N}_{2}$ quality BIP and helium quality Premier XSS, from Air Products, both equipped with manometer and pressure reducer), and the second one is a home-built chariot for the transport of polarized xenon. In this chariot, xenon is stored frozen in a glass coil inside a solenoid immersed in liquid nitrogen. The cold solenoid, driven by a car battery, delivers a magnetic field of $5 \mathrm{kG}$. Although no precise measurement was done, the xenon relaxation in these conditions is on the order of hours.

For sake of safety during the travel, all the devices (the heating system, the electric supply, the pumping group, and the laser diode unit) have been fixed on the aluminum frame through rivets or bolts. Working with Class IV lasers in a van requires some adjustments. For safety reasons, the rear doors of the van cannot be closed during operation (in case of emergency no fast exit would be possible). But to protect people from outside of the van from receiving accidentally a laser beam reflection, a removable plywood wall is added 

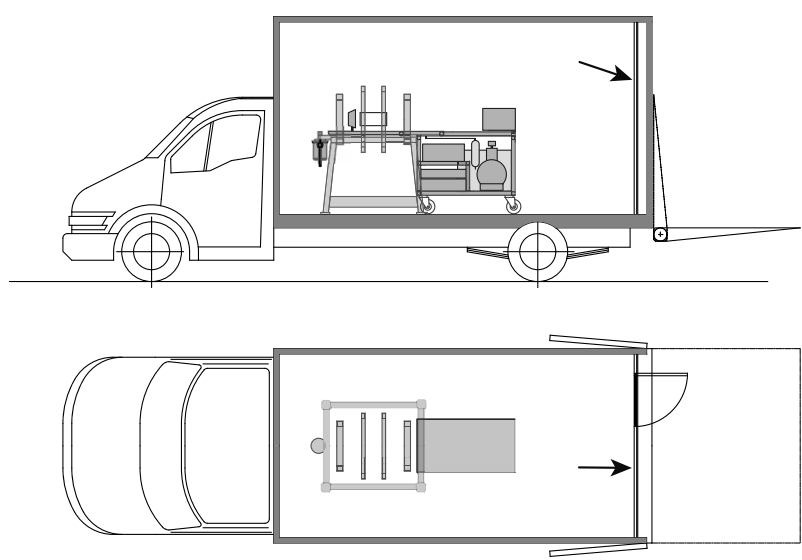

FIG. 3. Side and top views of the installation inside the van. The arrows indicate the plywood wall.

(Fig. 3). This wall contains a door, two electric outlets, and a passage for the warm air exhaust. Moreover a PVC pipe placed between the polarizer and the SEOP cell as well as an aluminum panel around the cell isolate the laser beam. These protections are also used when working in the fringe field of the imager magnet. Portable oxymeters (BW Technologies) come to complete the installation from the safety side. Periodically and after each van journey, some verifications and adjustments are necessary. The setpoint temperature of the diodes has to be adjusted in order to center the beam wavelength on the $\mathrm{D}_{1}$ line of the alkali metal. This is done by using a fibered optic spectrometer (AvaSpec Avantes Fiber). Also, vibrations during the travel as well as plugging and unplugging the fiber on the polarizer can cause deviation from the optimal setting of the quarterwave plates. They must be optimized before the first SEOP experiment.

In order to test the ease of use of our mobile SEOP setup, we went to perform hyperpolarized ${ }^{129} \mathrm{Xe}$ NMR experiments in the Centre de Biophysique Moléculaire (CBM) in the CNRS Campus of Orléans. Here, the van was parked few meters far away from the MRI laboratory. Among the first experiments, estimation of the xenon polarization in the gas phase was performed. Fig. 4 left shows the one-scan ${ }^{129} \mathrm{Xe}$ NMR spectrum performed after optical pumping (recorded at room temperature), as well as the Boltzmann signal obtained after having frozen xenon, introduced di-oxygen, and let the sample return to room temperature inside the $9.4 \mathrm{~T} \mathrm{NMR}$ magnet during $10 \mathrm{~min}$. For this experiment, polarization in the gas phase was estimated to 0.17 (ca. 19000 times the Boltzmann polarization at this magnetic field). Typically, polarization values between 0.15 and 0.25 are routinely obtained. This is sufficient to record one-scan images with high signal-to-noise ratio (Fig. 4, right).

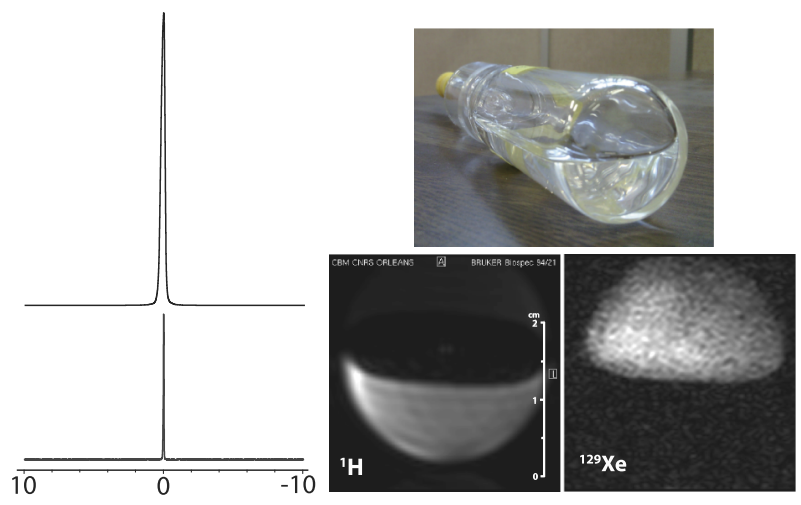

FIG. 4. ${ }^{129}$ Xe NMR spectra and images of gaseous xenon. Left: the top spectrum was obtained in one scan just after SEOP. Receiver gain $=4$. The bottom spectrum was recorded after introduction of oxygen, and 256 scans with the same flip angle pulse and a repetition time of 1 min (we checked that this was sufficient). Receiver gain $=16400$. Right: axial images of a cylinder filled to one half with a liquid. ${ }^{129} \mathrm{Xe}$ image obtained using a FLASH sequence. Data matrix $128 \times 128 ; \mathrm{FOV}=3 \times 3 \mathrm{~cm}$.

The simplicity of use and the robustness of our mobile SEOP setup providing milliliters of xenon per minute with high useful polarization ${ }^{7}$ pave the way to numerous experiments and collaborations. The lightweight of the device (that could be further miniaturized), the operating flexibility, and the production rate of the hyperpolarized species contrast with other techniques such as dynamic nuclear polarization and give versatility to the approach.

The authors acknowledge financial support from ITMO Cancer AVIESAN (French Alliance for Life Sciences and Health) within the framework of the Cancer Plan. They are also grateful to Sandra Même, William Même, and Frédéric Szeremeta for the preliminary NMR/MRI experiments in Orléans.

${ }^{1}$ T. G. Walker and W. Happer, Rev. Mod. Phys. 69, 629 (1997); M. S. Freeman, K. Emami, and B. Driehuys, Phys. Rev. A 90, 023406 (2014).

${ }^{2}$ T. Hughes-Riley, J. S. Six, D. M. L. Lilburn, K. F. Stupic, A. C. Dorkes, D. E. Shaw, G. E. Pavlovskaya, and T. Meersmann, J. Magn. Reson. 237, 23 (2013).

${ }^{3}$ P. Nikolaou, A. M. Coffey, L. L. Walkup, B. M. Gust, N. Whiting, H. Newton, I. Muradyan, M. Dabaghyan, K. Ranta, G. D. Moroz, M. S. Rosen, S. Patz, M. J. Barlow, E. Y. Chekmenev, and B. M. Goodson, Magn. Reson. Imaging 32, 541 (2014).

${ }^{4}$ S. E. Korchack, W. Kilian, and L. Mitschang, Appl. Magn. Reson. 44, 65 (2013).

${ }^{5}$ S. Patz, F. W. Hersman, I. Muradian, M. I. Hrovat, I. C. Ruset, S. Ketel, F. Jacobson, G. P. Topulos, H. Hatabu, and J. P. Butler, Eur. J. Radiol. 64, 335 (2007).

${ }^{6}$ H. Desvaux, T. Gautier, G. Le Goff, M. Pétro, and P. Berthault, Eur. Phys. J. D 12, 289-296 (2000).

${ }^{7}$ Xenon production rates of $5 \mathrm{ml} / \mathrm{min}$ with polarization of 0.15 were obtained for instance. 